\title{
Traditional Birth Attendants in Rural Gambia: Beyond Health to Social Cohesion
}

\author{
Stella Nyan₹i , Hawah Manneh², Gijs Walraven ${ }^{3}$
}

\begin{abstract}
Studies of traditional birth attendants over-emphasise the health dimension. Based on ethnographic fieldwork (utilising participant observation, individual interviews, group discussions, participatory rapid appraisal, and literature review) in The Gambia, this paper discusses the multiplicity of the role(s) of TBAs in their communities. As general healthcare providers, 'mothers of the village', gurus of religious and socio-cultural rites, repositories of society's secrets, economic survivors, village leaders and elders, TBAs contribute to the 'gum that holds society together'. They actively engage in the political, economic, cultural, religious, gender, health and wellbeing of their societies. TBAs are important for social cohesion and welfare; not mere health practitioners. Reflections about TBAs open a window into understanding the wider rural Gambian society.

Abstract $=(116$ words) (Rev Afr Santé Reprod 2007; 11[1]:43-56)
\end{abstract}

\section{RÉSUMÉ}

Les sages-femmes traditionnelles en Gambie rurale: Au delà de la santé vers la cohésion sociale Les études conscrées aux sages-femmes traditionnelles mettent trop d'accent sur l'aspect de la santé. Se fondant sur des travaux éthnographiques sur le terrain (à l'aide de l'observation participante, les interviews individuelles, les discussions en groupe, l'évaluation rapide participative et les documentations) en Gambie, cet article étudie la multiplicité des rôles des SFT dans leurs communautés. En tant que prestataires générales des services de santé, les "mamans du village", les grourous des rites religieux et socio-culturels, les dépositaires des secrètes de la société, les survivantes économiques, les dirigeants et les aînées dans le village, les SFTs contribuent à la "colle qui tient la société ensemble". Elles s'engagent activement dans le bien-être politique, économique, culturel, religieux, du genre et de la santé de leurs société. Les SFTs sont importantes pour la cohésion sociale et le bien, pas simplement en tant que praticiennes de santé. Les reflexions sur les SFTs ouvre une fenêtre sur la compréhension de la généralité de la société rurale gambienne. (Rev Afr Santé Reprod 2007; 11[1]:43-56)

KEY WORDS: Traditional birth attendants, reproductive health, Africa

${ }^{1}$ London School of Hygiene and Tropical Medicine, Keppel St., London WC1E 7HT. snyanzi@yahoo.com

${ }^{2}$ Medical Research Council Laboratories, The Gambia.

${ }^{3}$ Secretariat de Son Altesse l'Aga Khan, Aiglemont 60270, Gouvieux, France 


\section{Introduction}

Research about traditional birth attendants (TBAs) tends to over-emphasise the over-arching dimension of health. Some scholars ${ }^{1,2}$ recognise the need to move beyond narrow definitions of TBAs as people who assist women in childbirth because they indeed provide care at puberty, during pregnancy, labour, postnatal period and give advice about childcare. Hence they suggest replacing the label TBA with 'traditional midwife'. Several studies which claim to investigate the 'expansive role' of TBAs are still limited to considerations bounded within the category of health; including child spacing, family planning, prevention of sexually transmitted infections, HIV/AIDS, promotion of immunisation, breastfeeding, oral rehydration therapy, hygiene, nutrition, anaemia, resuscitation, malaria, health education, and health research. ${ }^{3-7}$

Our ethnographic study sought to understand the different roles that TBAs play in rural Gambia, exploring within and beyond metaphors of health in order to examine broader socio-cultural constructs.

\section{The position of TBAs in the primary healthcare system}

The Gambia adopted primary healthcare as the basis of national health policy in $1978 .^{8,9}$ This programme developed in the early 1980s. It includes the classification of primary healthcare key villages based on size and population of 400 or more, so that they receive Community Health Nurses (CHNs) who are trained by the Medical and Health Department and paid from central funds provided by international donors and government. ${ }^{8,10} \mathrm{CHNs}$ are the link between village-level primary healthcare services and referral services available at dispensaries, health centres and hospitals. Each of the CHNs is responsible for the supplies, supervision and continuing education of the village health workers (VHWs) and trained TBAs in about five primary healthcare key villages. ${ }^{11}$
TBAs are an integral part of the primary healthcare system in The Gambia. Before the establishment of the above programme by government, TBAs were already practising in the communities. In primary healthcare key villages, the community under the leadership of their village development committees (VDCs) select two out of the existing TBAs, to attend the centrally organised training as midwives. This generates resources within the community, contributing to the village healthcare system. According to UNICEF reports, in 1997 there were 460 trained TBAs, and 52 assistant TBAs nationwide who conducted half of all the deliveries. ${ }^{12}$

\section{Study setting}

We conducted fieldwork among TBAs from settlements surrounding Farafenni, in the North Bank Division of The Gambia. Though a busy peri-urban border town, Fararenni is surrounded by several scattered hamlets and villages of varying sizes.

The main economic activity is agriculture involving the growing of rice, groundnuts, millet and sorghum for domestic use and to supplement household income. The most common tribes are the Mandinka, Wollof and Fula. Though not always ethnically homogenous, many small villages are organised along and cohere through tribe, with village-members often claiming common descent. Islam is the predominant religion and impacts upon the local way of life and culture. Although formal education levels are mostly low for adults - particularly the women, the majority of men and women attend Quaranic school. Polygyny is common: while more than half the women have one or more co-wives, more than half the female adolescents aged between fifteen and nineteen years are married. ${ }^{13}$ Furthermore, the total fertility rate is 7.5 births per woman, mean birth interval is 33 months and only $9 \%$ of women use either traditional or modern contraception. TBAs attend to most of the sexual and reproductive health needs of the women.

African Journal of Reproductive Health Vol. 11 No.1 April 2007 


\section{Methods}

Qualitative data were collected using ethnographic participant observation, semi-structured questionnaires, in-depth interviews, focus group discussions, and participatory rapid appraisal (PRA) techniques ${ }^{14}$. Six CHNs who were affiliated to the MRC Laboratories provided us with lists of the villages in which they operated. In addition they purposively selected two names out of the trained TBAs they were supervising in each village. In total, our initial sampling frame for the TBAs consisted of six circuits, 34 villages and 68 names of TBAs. In order to obtain access to the TBAs, we involved the CHNs in the mobilisation, sensitisation and recruitment phases of fieldwork. We visited each of the TBAs in their homes in order to gain an appreciation of the diverse social environmental sub-contexts through participant observation. After the information sheet was explained, verbal consent was obtained from the participants. Eight TBAs had travelled to Farafenni for training, and two did not consent to participate in the study because they did not want to be recorded on audio-tape.

Fifty-eight TBAs responded to an initial semistructured interview. Thereafter 37 TBAs chosen for their ability to express themselves and willingness to continue participating in the study, took part in follow-up in-depth interviews which further pursued three main themes: the role of TBAs, motivation factors, and challenges that they encounter. Eight focus group discussions with TBAs were organised based on geographical proximity of the participants and ethnicity. Since circuits comprise of villages which are close to each other, uni-lingual circuits had one focus group discussion each, while two circuits were split up into two groups each because of language barriers created by inherent tribal differences. We hoped that the tribal homogeneity of the groups would enhance discussion. Furthermore, since the TBAs were united by their vocation and often attended joint training sessions together, we believed that they would easily interact with each other.

African Journal of Reproductive Health Vol. 11 No.1 April, 2007
An interactive PRA research and feedback session was conducted with all the TBAs who were willing and available from the six circuits, their CHNs and members of the Divisional Health Team (DHT) who are responsible for teaching and coordinating the trained TBAs. Data from the TBAs were triangulated with qualitative data from key informant interviews with the CHNs and DHT. In addition, three focus group discussions were held with women who delivered in the villages but without the help of a TBA.

All the interviews and discussions were conducted in the local languages, recorded on audio-tape, transcribed verbatim, translated into English and together with field-notes, entered into computer where they were subjected to discourse analysis using Atlas.ti 4.2 (Scientific Software Development, Berlin). Demographic data from the semi-structured questionnaire were analysed using Epi Info 6.0 (Epidemiology Program Office Centres for Disease Control, Atlanta).

\section{Results}

This paper mainly focuses on data from the TBAs; other data are analysed elsewhere ${ }^{15}$. The names of people and places have been changed in the presentation of results in order to conceal their identity.

For contextual and conceptual purposes, the label TBA here specifically refers to lay birth attendants who did not obtain formal western education or biomedical training but rather learnt their profession through induction. Unlike other primary healthcare contexts, it is some of these already practising but lay birth attendants are selected to attend an average of four weeks of basic obstetric training by government. Thereafter they work in conjunction with a village health worker and a CHN who is formally trained and certified in nursing and/or midwifery. The TBAs in the study are very much part of the traditional institution, with the exception of having recognition to practise after government training. All the TBAs were female. Their reported age 
ranged from 34 to ninety years, although several mentioned they were guessing their ages. Most women were aged between 61 and 80 years. Only seven women reported that they were less than 40 years old. All the participants were Muslims. The majority (37/58) were Mandinka, followed by the Wollof (17/58) and Fula (4/58). Fortyeight TBAs were married, with 9 of them specifying that they were in polygynous marital unions. Ten were widowed. Only one woman had acquired some formal education. Most of the TBAs $(53 / 58)$ had attended Quaranicschool. Of these, 3 had also attended adult literacy classes. Four TBAs had neither form of education.

\section{TBAs as general healthcare providers}

Similar to other contexts where primary healthcare is established, these TBAs provide general healthcare and support to their communities - over and beyond the sphere of reproductive health. Not only do they attend to women and/ or their babies during the antenatal, delivery and postnatal periods, but they are also often the first point of call for other community members when ill-health is suspected or it strikes. Due to their reputation as 'trained' healthcare providers, villagers frequently consult them in events of illness - be it related to pregnancy or not. They diagnose, prescribe treatment (such as paracetamol for pain, chloroquine or melania leaves for malaria, ointment or herbal remedies for skin disorders) and often treat different ailments among individuals. Where cases are too complicated to treat, the TBAs said that they often refer these to either the VHW, the CHN, a health centre or a marabout - Islamic faith-healer. The study participants reported that the villagers have more confidence in the services offered by TBAs because they know that the DHT frequently offers them refresher training courses. In addition to treating individual patients, these TBAs provide a diverse range of health services to their communities such as promotion of environmental hygiene, nutrition, sanitation, health education including teaching about prevention of malaria, preparation and use of oral re-hydration salts, promoting bed-net use, immunization programmes, facilitating health research, etc. In addition to more bio-medical therapeutic options recommended during the training sessions, these TBAs also offer traditional medicines, herbal concoctions and faith healing through Islamic prayers.

\section{Mother to the village}

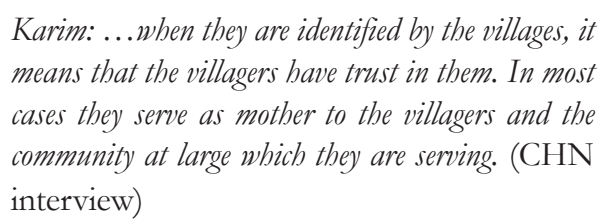
means that the villagers have trust in them. In most cases they serve as mother to the villagers and the community at large which they are serving. (CHN interview)

The metaphor of 'motherhood' was variously used throughout the discussions in reference to the significant role of these TBAs. While discussing the criteria that villagers use to select a potential candidate to be trained as a primary healthcare TBA, one of the conditions that the study participants mentioned is the fact that she must be known to have physically produced at least one child of her own. This rhymes with the prerequisites stipulated by the Department of State for Health.' The majority of the TBAs in the study had children; only two women reported that they did not have any biological children, although they had adopted ones.

Demographic data about the number of children that the study participants had was initially difficult to comprehend because not only did many TBAs claim to have more than ten children each, but also some claimed children whom we observed as too young to be their biological offspring. Forty-eight TBAs had lost at least one child through death. Further exploration through probing during individual interviews revealed that many $(25 / 58)$ of the TBAs had adopted children ranging from one to six. Some of the adopted children were biologically related to the TBAs, including grandchildren, nieces and nephews. However there were some others who were not

African Journal of Reproductive Health Vol. 11 No.1 April 2007 
relatives of the TBAs but were 'given' to them to raise by parents who admired positive attributes in the women. A few of the children were reported to be orphans. These 'social' children are not distinguished from 'biological' children in ordinary conversation. In fact there is no word for adopted children in the three vernaculars Mandinka, Wollof and Fula.

Unlike contexts where TBAs are reported to experience conflicts and competition from the VHWs and the trained professional healthcare workers including the CHNs and health centre staff, our study participants reported that they related amicably with their professional supervisors. All the CHNs in the study confirmed that their relationships with the TBAs they supervised were characterised by mutual respect, even during those times when there was a difference of opinion or when mistakes were made. Again, the metaphor of 'motherhood' was employed to explain the nature of relationship between the TBAs and the CHNs.

Interviewer: What are the different attitudes your TB As have towards you?

Bojang: Eh, very cordial. I am really impressed about their attitude towards me. We all have mutual respect and understanding for each other, between us. Because all of them appear like my mother. So I have given them the full pledged respect. And also they are giving me the full pledged respect as their senior son. (CHN interview)

Interviewer: Please comment on your interaction with the other healthcare providers in your area like the CHNs, SRNs, VHWs.

Fatou: For us in Kumikunda, we work as a family with other healthcare providers. Our meeting environment is always happy and friendly. For most of them are our grandsons and daughters. So they are friendly.

Hawa: There are no majorproblems between us. Our interactions are always in a friendly environment. We are just like grandmothers and they are grandchildren. (Focus group)

\section{Custodians of women's secrets}

Famatading: If you are selected as a TB $A$, you should be secretive. To be a TBA is to keep secrets.

Yaya: As she has just said, it is due to trust and confidence which makes the villagers to select you as a TBA. If the villagers didn't have trust in you, they would not have confidence in you to become their TB $A$. First of all a TB $A$ should be ever ready because a woman in labour does not have all her sense due to pain. So the TBA should also be mad like the woman in pain, because a person does not know what to do. You the TBA should help her, have patience for her and secure her too. (Focus group)

Natou: ... you will find difficulties but you have to bear it all in secrets, because this is the reason of being a TBA. Sometimes you will need to cover all the difficulties and make it a sealed secret and let no one know about it. (Focus group)

A frequently mentioned characteristic essential for a good TBA is the ability to be discrete, keep confidences and 'not to be a talkative who gossips about people's secrets'. In-depth inquiry revealed that TBAs are often consulted by women of all ages about a myriad of personal issues including physical illnesses of their bodies, mental frustrations causing worry or depression, social problems concerning relationships with other individuals (particularly husbands, co-wives and mothers-in-law) or groups in the communities, financial shortages, material lack in the home, etc. Many TBAs reported that 'some people open up a lot and they trust us too much'. TBAs handle personal and sensitive information about infertility, promiscuity, children conceived and born out of wedlock, abortions, miscarriages, sexually transmitted infections, impotence, marital problems; all of which could cause social stigma or ostracisation when revealed to the wider community.

Out of all the people within a village, TBAs are the only ones who have the socio-cultural permission and privilege of access to participate in the conception, pregnancy, labour, delivery and 
post-natal life of women they are not related to in African societies. In this particular context, the study participants claimed that many people resist the use of both traditional and modern contraception particularly because it opposed Islamic teachings of reproduction, fruitfulness and multiplication. This confirms earlier findings. ${ }^{14,15}$ Thus during the focus group discussions, some TBAs said that they cannot distribute contraceptive pills to women in their villages even though there was a Family Planning promotion campaign in the Division. They claimed that if they were known to encourage or give contraception, they would lose the confidence of the village elders and their reputation would be soiled in the community.

However, some other TBAs reported that even with the prevailing socio-cultural and religious resistance to using contraception, they do provide advice and information as well as distribute contraceptive pills to women who need them. They stressed the need to be secretive and keep the knowledge of this practice confidential, lest they jeopardise the social wellbeing and acceptance of their clients. This was confirmed by some of the CHNs and members of the DHT whom we interviewed.

Furthermore, as they perform their reproductive work, TBAs obtain access to and knowledge of the 'private parts' of women. When girls mature and cross the threshold into womanhood, some components of their physical anatomy become closed-off to the public. Physical exposure and knowledge of the pubis, vulva and vagina are usually only accessible to the individual woman and her sexual partner(s) (in cases of a healthy body) in this socio-cultural context. In the study area, deep socio-cultural and religious values proscribe against 'a woman exposing her female body to the public' and prescribe a decent dress-code of long and wide garments or wrappers dropping slightly above the ankles. Covering-up is essential to socially establishing maturity, proper up-bringing, religious devotion and higher social standing. However, during antenatal check-ups, labour and delivery, dresses are discarded and women 'openup' their bodies to the TBAs for vaginal examinations, to deliver the babies and placentas, and for postnatal care.

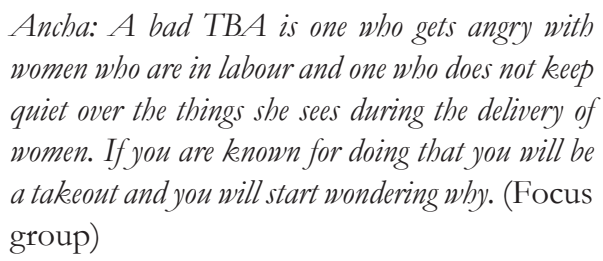

Soda: $A$ bad TBA, she will not keep secrets and talks a lot. When a TBA becomes a talkative, it is not good because anything you work on or discuss or see, you will talk about it. To talk about the way buman beings are brought into this world is unacceptable in society. This needs a secretive environment and its people. Anyone who misbehaves like this way, you are doing it from your own desire. (Focus group)

\section{Gurus of socio-cultural rituals}

During the social mapping exercises conducted in each village as we sensitised the village elders about the study, we asked them for names of individuals who were knowledgeable about the different cultural rites and rituals practised by the villagers. In all cases, the TBA was the first female name to be mentioned, specifically because TBAs are in charge of many of the socio-cultural ceremonies that celebrate the different rites of passage that are collectively honoured in this context. These include birth, naming ceremonies, marriages, circumcision - both male (as religious initiation into Islam) and female (for cultural identification as a woman), and funerals.

At birth, most of the TBAs reported that they cut the umbilical cord of the baby. Some TBAs also bury the expelled placenta at the back of the mother's house - which is often the bathroom, as a symbol to break infertility. Several participants reported that they also bathe the baby and press his body for the first seven days, as

African Journal of Reproductive Health Vol. 11 No.1 April 2007 
well as minister to its mother. As the body of the baby is still soft and the bones are easy to reshape, TBAs said that it is important that body parts like the ears and nose are regularly pulled into proper shape and size, the waistline is massaged so it becomes smaller than the trunk and hips, the arms and legs are pulled and exercised for strength, and the head is softly pressed into shape using a concoction of shea butter and herbs.

According to Islamic tradition, the baby is given a name and prayed for by the Imam (Islamic leader) and the village elders seven days after birth. This naming ceremony is often collectively celebrated with prayers, jubilation, feasting, music, dance and fanciful dressing. Both maternal and paternal relations from far and wide join the family and villagers to witness the naming of the baby. Many of the TBAs reported that they are often invited to the naming ceremonies of the children they help to deliver, and offered the greatest status at this function which involves shaving off the baby's hair, handing the child over to the elders and Imam to give it a name and pray for it.

\section{Khadijatou: In this village, if there is a naming ceremony, they always wait for us the $\mathrm{TB} A$ s to arrive at the occasion. The honour is given to the TBA to bring the baby to the elders to shave him or her. (Focus group) \\ Aida: ...during naming ceremonies we actively participate and share the joy with the people. \\ Fanta: We serve as the boss on that day. They will say, "The nurse is around." And they will give us kola nuts and food, raw meat and coos. (Focus group)}

In addition to the immediate paternal relatives of the baby, the TBA is the only other person who can choose a name for the baby. Furthermore, several babies are named after the TBA who delivered them, a practice believed to establish an eternal spiritual link between the two namesakes. Naming a child after someone is not only an honour, but also a sign of admiration for the TBA's character, skills and achievement by the parents of the baby since it is believed that the qualities in the TBA will transfer into the baby.

During participant observation in the villages, we encountered mothers challenging their daughters to behave as favourably as the TBA they were named after. During fieldwork, two babies were given the names 'Aminata Bah' after the ethnographic names of the foreign anthropologist (Stella). This was on the recommendation of the TBAs who assisted in the labour. The babies' parents did not personally know this anthropologist but acted on the wisdom of the TBAs, revealing the powerful and significant role of the TBAs in deciding about such domestic matters of families other than their own.

While the majority of our study participants reported that they were frequently honoured to play this role at the naming ceremonies, one vocal elderly participant expressed her frustration at being denied this honourable responsibility.

Jainaba: ... since we had our training, we were told that we the $T B A s$ are responsible for holding the baby during the naming ceremony. But in my village, I have never been given the honour to do it. Since after my training I have tried all my level best to get my honour and responsibilities, but none is being given to me. And no one has ever done something for me. We said, 'Give us the chance to hold the babies we delivered during the naming ceremonies so that we can get small presents to buy soap together with razor blades for our boxes', but still now we did not have this opportunity. The villagers are not doing anything for us at all. In our village we only get five dalasis for each delivery. As for me, I don't attend naming ceremonies. Let them send me my five dalasis. Hence I complained and said if we delivered a virgin, they should give us ten dalais because sometimes they receive a bundred or more dalasis during the naming ceremonies. So that I can share it with my colleague... each five dalasis. The villagers made the request a big quarrel. I left everything and forgot about it. Now when I deliver a woman, I will take care of the baby and the mother until the one-week postnatal care ends. On the naming ceremony day, I 
African Journal of Reproductive Health

send and ask for my five dalasis. I am continuing with them this system. I am not angry and I am not fed up. (Focus group)

\section{Female community leaders}

Neneh: If anything happens in the village and we appear, due respect is given to us as their TBAs of the village.

Soda: Yes, they do respect us.

Binta: The elders of the village do provide kola nuts to us when there is the whole village doing exercise. We share out these cola nuts to everybody present at the scene.

Dagga: During the christening ceremony, when the elders share the cola nuts into parts, the parts for the women are given to me to share out among all women at the gathering. (Focus group)

In these patriarchal societies where men dominate the local political scene, TBAs are an embodiment of female leadership. In-depth exploration revealed that many $(10 / 58)$ of these TBAs are the only female members of the elected VDCs, spearheading political discussions about the development of their communities; what projects to undertake, how to prioritise resource utilisation, how to source labour or manpower for the communal undertakings, finding markets for garden produce, village security, environmental hygiene, etc. These TBAs also sit among the unofficial council of elders when social meetings are held in the villages. Apart from politics at the village level, TBAs are also leaders or members of the different clubs or associations organised along divisions of age, interest area or activity. These associations (locally called kafoo in Mandinka or mbotail kompin in Wollof) form a composite part of the social organisation of rural life in The Gambia. ${ }^{14}$ Examples include the osusu which is a popular rotating saving scheme where a group of women regularly pull money and each of them takes the money in rotation (see Shipton $1990^{16}$ for detailed discussion), the agricultural kafoo or tesitoo in which women collectively labour on a communal farm and either share the harvest or the proceeds from the sales thereof, the kanyeleng which involves women who have lost several infants and the seet setal which involves regular communal cleaning of the compounds and public places in the villages. Several study participants reported that they were either the initiators or leaders of these associations, or members of the executive committees or just members, revealing that they are among the few women who actively participate in the local sociopolitics of their villages.

\section{Maimouna: I am the leader of the tesitoo committee. \\ Sainabou: Yes we are well recognized, because selecting someone to lead the whole committee, obviously all the due respect and dues will be given to the person. \\ Adama: In my village I'm the leader of the soap- making committee. I must approve everything taking place. (Focus group)}

Many TBAs believed that they were selected to go for training because of their renowned experience and seniority in assisting with deliveries in the villages. Women referred to as 'Senior TBA' were elderly. Their younger counterparts were called 'Junior TBAs'. During participant observation we noticed that many Junior TBAs revered and respected their senior counterparts to the point of seeking permission from them to participate in the study, scheduling their activities to accommodate the Senior TBAs' presences and absences, failing to criticise, confront or correct them when they erred, etc. While the reverence is conducive to better work relations between the two TBAs, it also complicates the supervisory role of the CHNS who sometimes need to correct and challenge the older TBAs who tend to forget procedures more often.

While several participants including the CHNs reported that TBAs are selected for training according to the criteria provided by government, a few TBAs reported that sometimes politicians influence the process of TBA selection by appointing their own relatives or friends, and

African Journal of Reproductive Health Vol. 11 No.1 April 2007 
thereby marginalising community participation. The VDCs were reported as sometimes being powerless to challenge the dictates of powerful individuals who usurp the position of TBA.

\section{Voluntary community workers for life? Economics of birthing}

There is no standard rate of payment for the reproductive health services of TBAs in The Gambia. Instead, VDCs are supposed to encourage their community members to support the TBAs specifically through providing labour for cultivation, sowing and harvesting on their farms. Many TBAs complained that this labour was not forthcoming. Instead they often had to work on their farms, rice-fields or backyard vegetable gardens themselves, in addition to all their other domestic duties and community responsibilities. Otherwise they would neither clear the bushes in time for the rains, nor sow expansively, nor ably fight off weeds and pests from their crops.

Kujeng: For example I went on training and my rice
was in the field, ready for harvesting. The CHN
came to inform me about attending the training
course. I told him, I cannot go because my rice was in
the field waiting. I am alone. No other person to do
it for me.' He said that the villagers would harvest it
for me. I accepted him and left for the training. But
as I left my rice field, is exactly how I found it when
I returned back. from the training. The villagers said
that what we the TBAs do receive from the training,
we know it. I heard it with my own ears. Nobody
narrated it to me. We leave it with God the creator
who knows all. Is it not that? (Focus group)

A few TBAs, however confirmed that their villages were enthusiastic in regularly providing this labour when it was due.

Another form of reward for the TBAs that was frequently mentioned in the discussions was monetary gifts and material donations given at the naming ceremony of the babies they delivered. The amounts of money mentioned ranged from 5 to 35 dalasis. Gift items included kola nuts, meat, fish, dresses, soap, rice or the food cooked for the ceremony. These amounts were not specified by the TBA, but decided upon by the individual parents and family members of the baby. However, many TBAs agreed that rates enormously varied because of the rampant levels of household inequalities in the villages. While some families gave out a lot in appreciation of the job done by the TBA, others could only afford so much, and a few others could not afford anything.

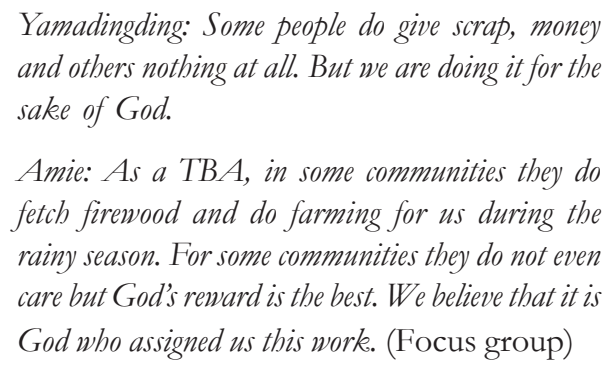

The greatest social reward that many TBAs appreciated and proudly spoke about was the recognition given at the naming ceremony when they participated in shaving the baby's head and carrying it to the elders for prayers and naming as discussed above. Though intangible, the TBAs seemed to cherish the memories of such occasions. They also believed it raised their social placing within the community, gaining them more honour and respect as elders.

While many $\mathrm{CHNs}$ agreed that the TBAs play a big role in the communities and stressed the need for government to initiate formal payments for their services, two of them pointed out that the TBAs were initially farmers before undertaking this job. Therefore they should continue to farm in order to feed themselves, their dependants and also have some surplus to sell in order to supplement their household incomes.

Habib: TB A work does not mean you are not supposed to do anything else for your personal or farming upkeep! (Key informant interview)

In sharp contrast to the reported partial commitment of some of the community members to support their TBAs, our study participants 
claimed to take their appointment as the trained village TBA seriously. To them, it was 'a life commitment', not a mere job from which they could one day retire.

\section{Kumba: ... from the day you are selected and trained, it is expected of you to render services until they day you die or when you get too old, no strength, poor eyesight. Then you are due for retirement. (Focus group discussion)}

In confirmation of their total commitment to rendering services to their communities, the TBAs narrated experiences of summons to attend to women in labour that often came late in the night, or in the middle of a storm, or found them in the middle of family get-togethers, or doing much-needed domestic chores or required giving too much of themselves. In most of these cases, they claimed that they practically dropped whatever else they were doing and ran to attend to the labouring women.

When asked whether government paid TBAs for their work, there was a general misconception about the training allowances offered by the DHT to facilitate the TBAs to attend the sessions. Many TBAs explained that the kola nuts, meals, transport allowance and per-diems provided during these training sessions are government's payment for the services that TBAs render to their communities.

Five out of the six circuits from which we recruited our study participants were all part of on-going research with the MRC. As a result, the TBAs from these 5 circuits repeatedly hailed the benefits gained from participating in the MRC interventional research. They also reported that the joint collaboration between MRC and the DHT office had provided a number of solutions to some problems they were initially experiencing including lack of safe delivery kits, delay of restocking drugs and supplies, requisition of referral forms and regular supervision.

\section{Discussion}

This paper examines qualitative data gathered among TBAs in rural Gambia using a combina- tion of research techniques: ethnographic participant observation, in-depth individual interviews, focus group discussions and PRA. Comparisons are made between data sets from the TBAs and key informants including the CHNs who supervise the TBAs and members of the DHT which is responsible for the management, coordination and monitoring of the health system in North Bank Division. The study participants were purposively selected because we wanted women who were not only knowledgeable about the experiences of TBAs, but also able to coherently express themselves in both individual and large or small-group settings. Thus we cannot exaggerate the generalisability or representativeness of our findings to typify all TBAs in rural settings. However, the paper provides a detailed in-depth understanding of the values, norms, practices and experiences of these TBAs within this particular socio-cultural setting, and thereby highlights the multiplicity of roles that TBAs play in their communities. It discusses the diverse responsibilities which beg for the TBAs attention, time, resources and commitment.

Interestingly, while the TBAs needed detailed probing during interviews about their role(s) outside the realm of health, the CHNs and DHT members were quick to respond to this question. This could be as a result of 'research fatigue syndrome' due to considerable involvement in health research and interventions, such that these TBAs assess researchers' topic of interest and assume answers they are expecting to hear ${ }^{17,14}$ Therefore it is essential that flexible research methodologies which can challenge and surpass the generation of stereotypical responses are innovatively adopted for this and other such study populations. Our methodology triangulated traditional ethnographic research techniques with PRA. Participant observation sessions particularly enriched our knowledge about the day-to-day realities of the TBAs, which often went unmentioned in the formal interview sessions. The PRA workshop was a chance for collective mutual

African Journal of Reproductive Health Vol. 11 No.1 April 2007 
feedback and the TBAs criticised, challenged as well as confirmed our initial preliminary findings.

An alternative explanation for the TBA's hesitation to acknowledge the bulk of their functions could perhaps be that they have learnt to underplay the significance of the multiplicity of roles that they play in their communities because of the over-emphasis on the 'midwifery role' by practitioners and policymakers who subscribe to the positivist or biomedical model of interpreting health and wellbeing to narrowly focus only on issues of the body. However our data revealed that TBAs minister not only to the physical reproductive health needs of women in their communities, but also to the social, political, cultural, religious, gender, development and economic needs. Therefore health policymakers and programme implementers interested in working with or designing interventions for TBAs must appreciate the diversity encompassed within the TBAs' lay paradigm of wellbeing and the resultant load of duties and responsibilities that these women have. Otherwise, it is possible that programmes which further assign new tasks and roles to the TBAs (because they are an influential social group which is easy to target) may perhaps be over-burdening. In such cases the TBAs are spread out too thin, often compromising their efficiency and effectiveness at implementing programmes. However, an appreciation of the day-to-day burden placed upon TBAs would lead to better designed programmes and policies based on a consideration of the minimum possible combination of new and old duties, roles and responsibilities in order to optimise performance and output.

As general healthcare providers, the TBAs attend to the health needs of both the individuals and diverse social groups in the villages. In practice, TBAs variously combine diverse therapeutic models ${ }^{18,19}$ depending on the nature of symptoms portrayed on the patient. They synchronise both lay aetiologies and frameworks of interpreting health and illness, with more professional ones including African traditional medicine, Islamic faith healing and Western bio-medicine respectively. Their appreciation and utilisation of the prevalent multiple therapeutic options makes them significant unifiers who link the gap between lay users of healthcare services and diverse professional healthcare service providers. In essence, TBAs are a link between the lay community members and the professional healthcare sector not only because of the referrals they make to the health centres, but also due to the fact that they themselves (often in conjunction with the VHWs) appeal to both models of healthcare to attend to most forms of illness in the villages.

Unlike biomedicine or other traditional healthcare contexts which do have some male TBAs, our study participants reported that traditionally the institution was strictly restricted to only female practitioners. They strongly believed that young rural women would definitely prefer to deliver under the supervision of another woman, to having a male attendant. Thus they argued that the practice of having male midwives alienates or disregards the wishes of their younger female attendees. Contrary to this, five out of the six CHNs in the study were all male midwives who argued that the rural populations had come to accept the introduction of male practitioners into this historically female space. They further stressed that the schools of nursing and midwifery in the country had large male student populations. There is an urgent need to conduct further research about the effect of having male midwives, on the levels of utilisation of reproductive health services particularly in rural and highly religious social cultural contexts where gender differentiation occurs along strict prescriptions and proscriptions.

The metaphor of motherhood is variously employed to explain the significance of the TBAs in their domestic, public and official worlds. As mothers, they were responsible for reproducing and raising their biological offspring in addition to facilitating the safe reproduction of the village 
members in their communities. It is their duty to provide safe care to labouring mothers and their babies. The TBAs also adopt and foster several social children who may or may not be their blood relations, perhaps due to having experienced the death of biological offspring. Hence they nurture social offspring. According to Madhavan and Bledsoe $^{15}$, social reproduction is quite often a more important phenomenon than biological fertility in families. Another explanation for this practice could be the fact that their pronounced position in societies makes TBAs easy targets for people who cannot afford to raise their children due to various reasons including growing poverty, rural-urban or cross-border migration in search of employment and better opportunities, remarriage in the case of women, etc. Therefore these parents 'give out' their offspring to the TBAs to raise. A study ${ }^{20}$ conducted in the same area reported that adoption, fosterage and giving out of children are widely practised cultural norms which contribute to the redistribution of wealth and negotiation of social rank in The Gambia.

Though they may not have a psychologist's couch, TBAs offer psychosocial counselling and therapy to members of their societies. As a common repository of women's secrets, TBAs provide an avenue for women to feel at ease, open up and reveal deep confidences to these mostly elderly females. Akin to the physical act of women opening up their most private physical body parts to the TBAs in order to solve their reproductive health needs, different society members including fathers, husbands, and sons of the village-women often consult and confide in the TBAs about their social problems. Clearly expressed in the words of a wise elderly TBA, 'Instead of hanging their soiled linen out in the public, they wash it out in our presence.' This process of symbolic cleansing is essential to the health and wellbeing of society because it helps create balance in events of social disequilibrium. Based on their age, experience and wisdom, the TBAs provide counselling and advice to both male and female, young and old members of their villages. It would be worthwhile to further investigate the support networks available to TBAs.

Rural Gambian villages are predominantly patriarchal hierarchies which are headed by a chief (locally called Alkalo), and a council of elders including the Imam. All the Alkalos of the villages from which we collected data were men. During participant observation, questions about the possibility of a female Alkalo always invoked laughter at the incredulity of the idea. Typical of African Islamic ethos, the place of women is 'at the back of their men'. In the public arena, men lead and women follow. However, TBAs are an embodiment of females who silently contest this gender stereotype because they are at the helm of leadership in their villages. Many TBAs were the only female members of their VDCs, and the council of elders. They actively participate in decision-making about the development of their communities. By western standards, the majority of the TBAs were uneducated and thus illiterate. However by local rural Gambian standards, these TBAs represent an educated female minority because most of them had indeed completed Quaranic school, which is locally presented as a male privilege. Therefore, the TBAs represent an empowered social group of women to the emic eye.

In The Gambia age and seniority are rewarded and revered because they are associated with greater experience, exposure and wisdom. The elderly are unreservedly respected whether or not they warrant it. Youths aspire towards old age. Gerontocracy is the most common form of leadership in the different villages because many Alkalos are septuagenarians or octogenarians. Even where younger Alkalos exist because they inherited the chieftaincy at their fathers' death, those who actually hold the decisive power and authority in these villages are often a clique of elderly men. ${ }^{21,22}$ This age-based hierarchy of power translates into seniocracy within the

African Journal of Reproductive Health Vol. 11 No.1 April 2007 
institution of TBAs, whereby seniority and older age predetermine the selection of particular women as the 'Senior 'TBA' who must be respected and revered by her junior counterpart, the villagers and other healthcare providers. This sometimes complicates the supervisory role of the $\mathrm{CHNs}$ who may need to commend the Junior TBA for a job well done, and yet reprimand the older Senior TBAs who tend to forget procedures more frequently.

Analysis revealed an interesting disparity between the reported high social value and public appreciation accorded to TBAs on one hand, and the seeming lack of support (whether material, financial, in service or kind) among some village members. This contradiction should be interpreted in the light of the current high inflation rates and depreciation of the value of the Gambian currency - the dalasi. While religocultural values prescribe generosity and reciprocation, rampant rural poverty restricts many villagers from meaningful giving. Consequently some villagers resort to offering support in kind by offering what they can afford. It is important that mechanisms are implemented for sustainable generation of resources for the TBAs so that their attention is not diverted to fending for their personal and domestic sustenance. Perhaps the VDCs should be invigorated to further enhance their role of reminding villagers to support their trained TBAs.

As general healthcare providers, 'mothers of the village', gurus of religious and socio-cultural rites, repositories of society's secrets, economic survivors, village leaders and elders, TBAs contribute to the 'gum that holds society together'. They actively engage in the political, economic, cultural, religious, gender, health and wellbeing of their societies. TBAs are important for social cohesion and welfare; not mere health prac-titioners.

\section{Acknowledgements}

We are grateful to Yusupha Dampha, Nankey Njie, Ansumana Manjang, Wandifa Fofana,
Arfang Kujabi, Lamin Samateh for mobilising the study participants. Emily Loppy, Yamundow Jallo, Ousman Bah, Sulayman Joof and Jarrai Barrow assisted with data collection. Tijan Cham and Ousman Bojang drove us to and from during fieldwork. We appreciate the TBAs for enthusiastic participation.

\section{REFERENCES}

1. Tremlett G. Working with traditional midwives. In: Stanfield JP (Ed.) Diseases of children in the subtropics and tropics, 4th Edn, London: Edward Arnold, 1991,94-95.

2. Piper CJ. Is there a place for traditional midwives in the provision of community-health services? Annals of Tropical Medicine and Parasitology 1997; 91(3):237-245.

3. Walraven G, Weeks A. The role of (traditional) birth attendants with midwifery skills in the reduction of maternal mortality. Tropical Medicine and International Health 1999; 4(8):527-529.

4. Menendez C, Alonso PL, Kinteh A, Mbohe B, Francis N, Greenwood BM. The contribution of traditional birth attendants to field research. Journal of Tropical Medicine and Hygiene 1993; 96: 175-178.

5. Kumar R. Effect of training on the resuscitation practices of traditional birth attendants. Transactions of the Royal Society of Tropical Medicine and Hygiene 1994; 88:159-160.

6. Staugaard F. Role of traditional health workers in prevention and control of AIDS in Africa. Tropical Doctor 1991; 21:22-24.

7. Miller LC, Jami-Iman F, Timouri M, Wijinker J. Trained traditional birth attendants as educators of refugee mothers. World Health Forum 1995; 16:151-156.

8. Greenwood AM, Bradley AK, Byass P, Greenwood BM, Snow RW, Bennett S, Hatib-Njie AB. Evaluation of a primary health care programme in The Gambia I. The impact of trained traditional birth attendants on the outcome of pregnancy. Journal of Tropical Medicine and Health 1990; 93:58-66.

9. Ministry of Health. Manual for the maternal and cbild health services. Banjul: Ministry of Health, 1993. 
10. Hill AG, Macleod WB, Joof D, Gomez P, Ratcliffe AA, Walraven G. Decline of mortality in children in rural Gambia: the influence of village-level primary health care. Tropical Medicine and International Health 2000; 5(2):107-118.

11. Bij de Vaate A, Coleman R, Manneh H, Walraven G. Knowledge, attitudes and practices of trained traditional birth attendants in The Gambia in the prevention, recognition and management of postpartum haemorrhage. Midwifery 2002; 18:3-11.

12. Gambia/ UNICEF. Situation analysis of children and women in The Gambia. Banjul: UNICEF, 1997.

13. Ratcliffe A, Hill A, Walraven G. Separate Lives: male and female reproduction in The Gambia, West Africa. Bulletin of the World Health Organization 2000; 78(5):570-579.

14. Nyanzi S, Bah O, Joof S, Walraven G. Combining PRA techniques with ethnographic research among traditional birth attendants in The Gambia: a methods paper. Qualitative Research 2007; 7(2):25-43.

15. Nyanzi S., Manneh H., Walraven G. "Saving two lives": roles, challenges and motivating factors for TBAs in rural Gambia. Health Care for Women International (forthcoming)
16. Shaw M, Jawo M. Gambian experiences with Stepping Stones: 1996-99. PL A Notes 2000; 37:73-78.

17. Madhavan S, Bledsoe $\mathrm{CH}$. The compound as a locus of fertility management: the case of The Gambia. Culture, Health and Sexuality 2001; 3(2):451-468.

18. Shipton P. How Gambians save - and what their strategies imply for international aid. Washington DC: World Bank, 1990.

19. Helman CG. Culture, health and illness: an introduction for health professionals. Oxford: ButterworthHeineman, 1994.

20. Kleinman A. Patients and healers in the context of culture. Berkeley: University of California Press, 1980.

21. Sommerfelt T. Shares and sharing; dynamics of exchange, identity, rank and power in a Gambian town. Unpublished Thesis, Department and Museum of Anthropology, University of Oslo,1999.

22. Aguilar MI. (Ed.) The politics of age and gerontocracy in Africa: ethnographies of the past and memories of the present. Trenton, New Jersey: Africa world Press, 1998.

23. Humer J. Gerontocracy as a tradition and mirror of the future: the case of Sidama. The Sidama Concern 1998; 3(3):5-10. 